\title{
$\mathrm{PH} 103$ actualidad
}

\section{EI IAPH y la Universidad de Huelva lideran un proyecto sobre la ostra plana en el litoral andaluz}

\author{
EI IAPH, junto con la Universidad de Huelva, codirige el proyecto con nombre Criterios paleobiológicos \\ para el conocimiento y gestión de la biodiversidad. La ostra plana en el litoral andaluz. Financiado por el \\ programa operativo FEDER Andalucía 2014-2020 para ser desarrollado entre los años 2020 y 2022, su \\ objetivo es mostrar la importancia de los registros arqueológicos orgánicos y paleontológicos en la gestión \\ de los recursos naturales de los actuales ecosistemas.
}

\begin{abstract}
Eloísa Bernáldez Sánchez, Esteban García-Viñas | Laboratorio de Paleontología y Paleobiología, Instituto Andaluz del Patrimonio Histórico
\end{abstract}

URL de la contribución <http://www.iaph.es/revistaph/index.php/revistaph/article/view/4892>

Entender el pasado es esencial para comprender lo que somos hoy. Desde esta perspectiva se demuestra que el patrimonio histórico y paleontológico es un soporte imprescindible desde el que conocer el estado actual de algunas especies faunísticas de interés natural y comercial como es la ostra europea u ostra plana. En concreto, en este proyecto se están desarrollando tres actividades específicas:

1) Establecer el origen y evolución espacio-temporal de la especie Ostrea edulis Linneus, 1758 en el sur de la Península Ibérica como referencia de la situación actual de esta especie. Para ello se analizará su presencia en los concheros antiguos de yacimientos paleontológicos, arqueológicos y actuales, tanto naturales como antrópicos.

2) Determinar las características biológicas de la especie en las vertientes atlántica y mediterránea actuales y antiguas con y sin intervención humana. Los análisis estadísticos de los datos de las medidas de las valvas de ostras determinarán las diferencias y similitudes en el tamaño y la forma de las poblaciones actuales y antiguas.

3) Correlacionar la distribución geográfica y las características biológicas de los ejemplares de ostras analizadas. Esto permitirá delimitar la distribución espacio-temporal de la especie y los cambios morfobiométricos experimentados a causa del impacto de la sobreexplotación humana.
El estudio se estructura en tres marcos de actuación comunes, dos de obtención de datos y uno de procesado, con aproximaciones diferentes dependiendo del registro tratado (paleontológico, arqueológico o actual).

Los datos directos se obtienen mediante recolección directa de ejemplares y/o revisión de colecciones. Los ejemplares de los registros paleontológicos y arqueológicos proceden de yacimientos o bien conocidos, que serán revisados, o bien excavados durante el desarrollo de este proyecto. Los ejemplares del registro actual se recogen tanto en bancos intermareales como valvas aisladas en concheros.

Los datos indirectos se obtienen mediante la revisión de bibliografía, el contacto con otros expertos y mediante entrevistas tanto a investigadores de las universidades y organismos públicos andaluces tales como administraciones de parques naturales y espacios protegidos costeros, como a ostricultores y otros profesionales con actividad ligada a la explotación del medio litoral (como buzos y pescadores).

Hasta la fecha hemos obtenido resultados muy interesantes. El dato más relevante es que o ha desaparecido la especie de nuestro litoral o está en vías de extinción. Otros resultados que nos interesan es obtener información de cómo eran las ostras sin intervención humana, es decir, cómo era la ostra autóctona para así reconocer 


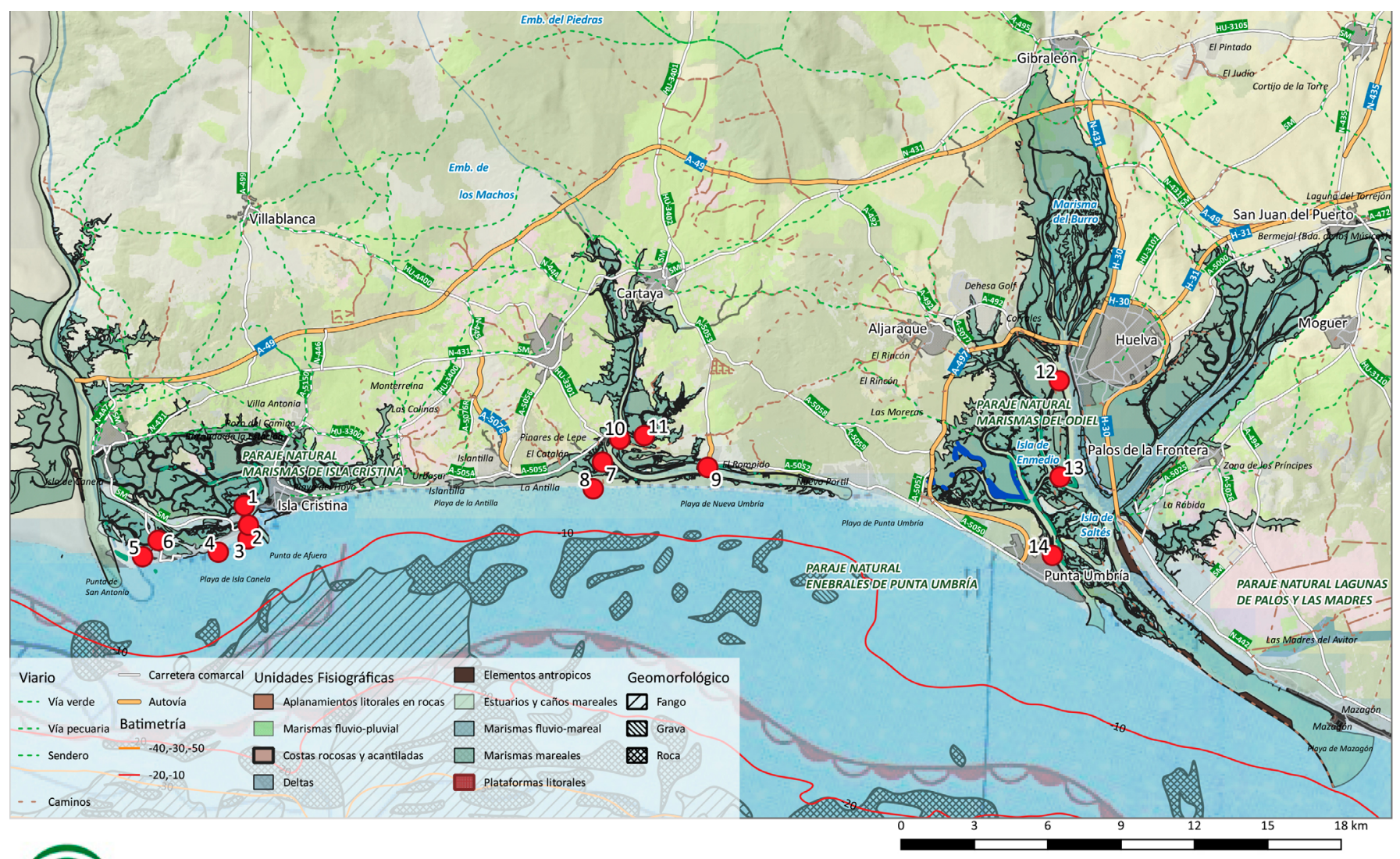

1. Instituto Andaluz del Patrimonio Histónico

Nera II wauna CONSEJERIA DE CULTURA Y PATRIMONIO HISTÓRICO

Sitios muestreados para la localización de especímenes de Ostrea edulis. Área entre los ríos Guadiana y Tinto/Odiel | mapa Fondo Gráfico IAPH (David Villalón Torres)

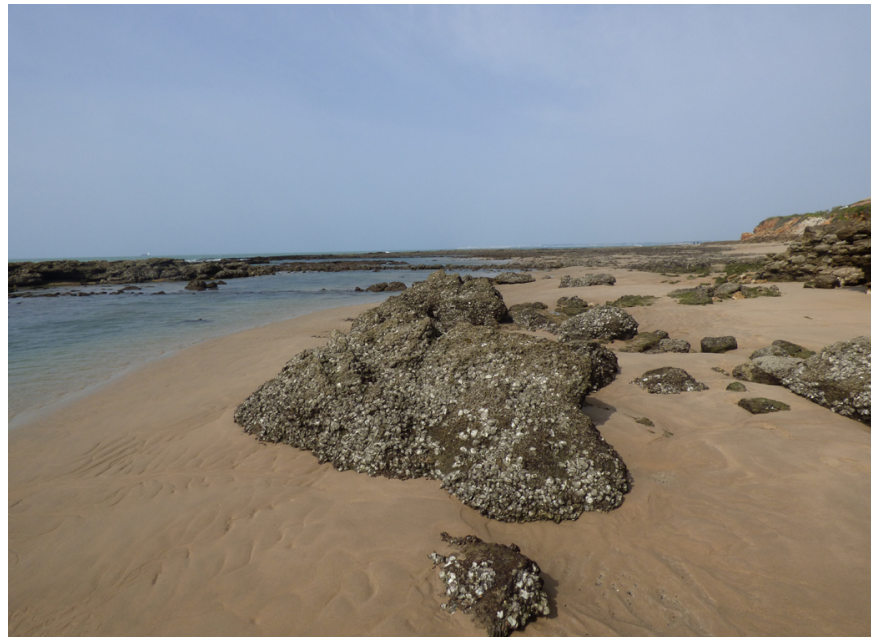

Banco de ostreidos, compuesto principalmente por ejemplares de Crassostrea sp. Playa de la Muralla (Chiclana de la Frontera) | foto Fondo Gráfico IAPH

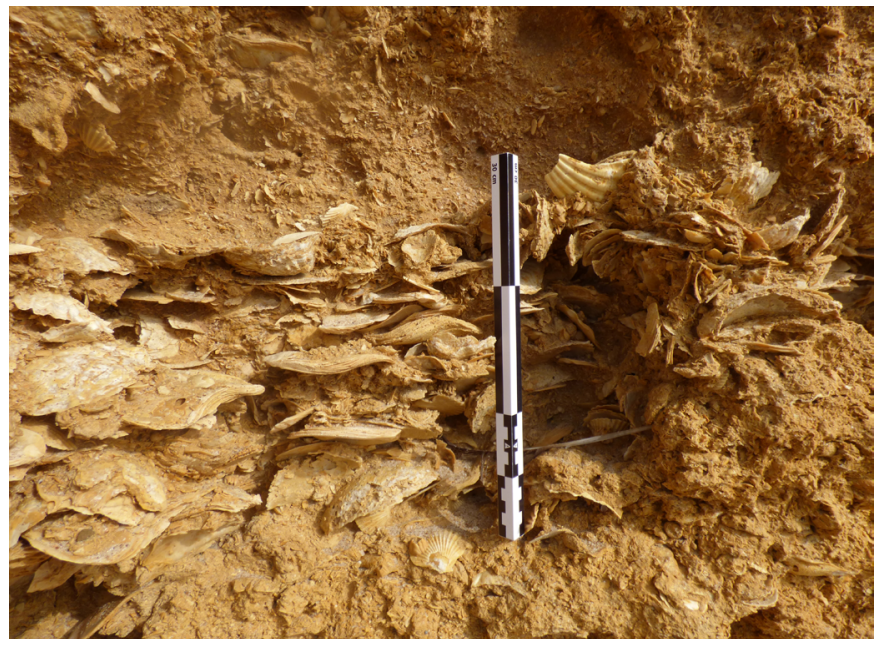

Nivel de ostras fósiles localizado en la playa de la Barrosa (Chiclana de la Frontera, Cádiz) | foto Fondo Gráfico IAPH 


\begin{tabular}{|ll|}
\hline Equipo de investigación & \\
\hline Investigadores Principales (IP) & $\begin{array}{l}\text { Eduardo Mayoral Alfaro² } \\
\text { Eloísa Bernáldez-Sánchez }\end{array}$ \\
\hline Equid Villalón Torres & \\
\hline Equipo de investigación & $\begin{array}{l}\text { Antonio Rodríguez Ramírez } \\
\text { Esteban García-Viñas }\end{array}$ \\
\hline Personal contratado & $\begin{array}{l}\text { Ana Guerreiro dos Santos } \\
\text { Fernando Sanguino González }\end{array}$ \\
\hline Equipo de trabajo & Jennifer Leonard \\
\hline
\end{tabular}

1 Instituto Andaluz del Patrimonio Histórico. 2 Universidad de Huelva. 3 Estación Biológica de Doñana

el impacto humano sobre esta especie. Este resultado nos lo está proporcionando los yacimientos paleontológicos localizados datados con anterioridad al comienzo del Cuaternario, hace 2,5 millones de años (Mayoral 1986). En este período los paleontólogos no han hallado yacimientos naturales de ostra plana y cuando las volvemos a encontrar están relacionadas con los yacimientos arqueológicos del Holoceno (últimos 10.000 años) coincidiendo con el desarrollo de las culturas más relevantes de nuestra historia. Las ostras las hallamos en escaso número en los yacimientos del paleolítico superior y en los medievales; y en abundancia en los paleobasureros fenicios, romanos y modernos de los siglos XIV al XVIII (la Pequeña Edad del Hielo). Trataremos de ver la relación entre estas culturas y el hallazgo de ostras en los paleobasureros $y$, aunque es muy posible que sean restos del consumo, podemos asegurar que se utilizaron como material de construcción. Aún hoy podemos ver los suelos de ostras de yacimientos fenicios en Málaga (calle Granada), o entre sillares de construcciones como la Catedral de Sevilla o la Real Fábrica de Tabaco (Universidad de Sevilla).

La diferencia más determinante entre las asociaciones de ostras estudiadas de distintas localidades y períodos la estamos hallando en la forma de las valvas procedentes de los concheros mediterráneos y atlánticos, las primeras son más alargadas que las segundas. Posiblemente esto esté relacionado con los resultados del análisis genético de Launley, Boundry, Ledu et ál.

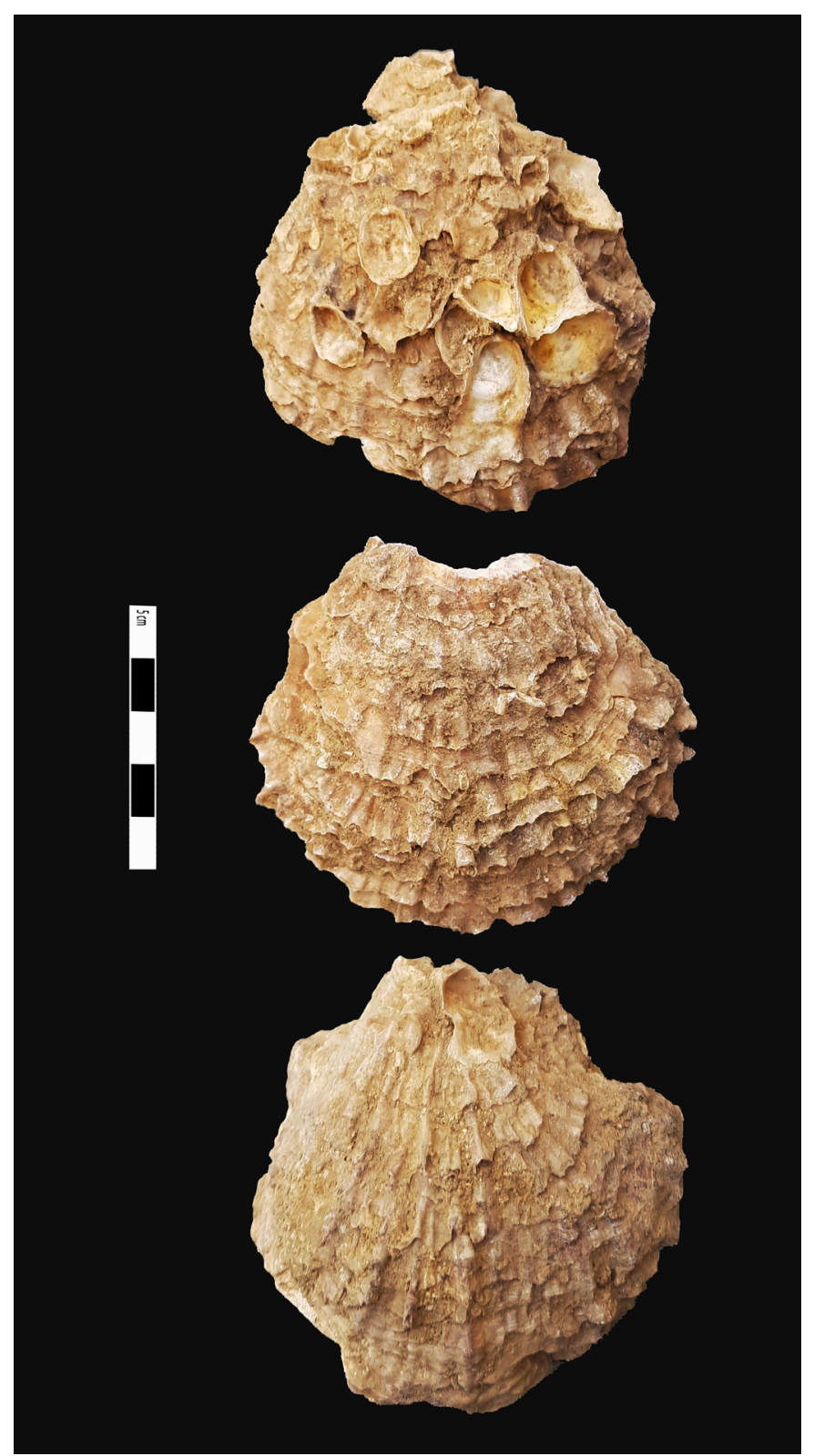

Valvas de ostra plana procedentes de estratos datados en el s. I d. de C. de la campaña de excavaciones de 2009-2011 realizadas en el teatro de Itálica (Bernáldez-Sánchez y García-Viñas, en prensa) | foto Fondo Gráfico IAPH

(2012), que hallaron diferencias genéticas significativas entre ambas vertientes, lo que está determinando dos comunidades distintas con el estrecho como frontera. La otra consecuencia de este estudio es que hay una diferencia de tamaño en momentos concretos de la historia; por ejemplo, en la segunda mitad del siglo XVI, cuando 
la población de Sevilla ascendió de 40.000 , en el siglo $\mathrm{XV}$, a 120.000 habitantes. En este momento el consumo de ostras debía ser muy popular puesto que el precio de un par de ostras era de cuatro maravedíes; teniendo en cuenta el precio de otros productos, parece que era una comida asequible a cualquier estrato social (BernándezSánchez y García-Viñas 2010).

\section{BIBLIOGRAFÍA}

- Bernáldez Sánchez, E. y García-Viñas, E. (en prensa) El patrimonio arqueológico orgánico en el Teatro de Itálica (Santiponce, Sevilla). Arqueología de los residuos en tiempos de Roma

- Bernáldez Sánchez, E. y García-Viñas, E. (2010) Indirect detection of changes in Seville population studying size changes in oysters? Munibe Suplemento, n. ${ }^{\circ} 31$, pp. 208-215

- Launey, S., Boundry, P., Ledu, C., Bonhomme, F. y NaciriGraven, Y. (2002) Geographic structure in the European flat oyster (Ostrea edulis L.) as revealed by microsatellite polymorphism. Journal of Heredity, vol. 93, n. ${ }^{\circ} 5$, pp. 331-351

- Mayoral Alfaro, E. (1986) Tafonomía y paleoecología del Plioceno de Huelva-Bonares. Tesis doctoral inédita. Universidad de Huelva 